\title{
One Kind of Semi-automatic Loading Mope by Stair Climbing
}

\author{
Meng Kaixin ${ }^{1, a}$ \\ ${ }^{1}$ North China Electric Power University, Beijing, 102206, China \\ a18811360271@163.com
}

KeyWords: stair climbing device; mechanic design; four-bar linkage; power assisting device

\begin{abstract}
. with the quick development of express industry, the courier needs to safely and quickly send things to customer house. As for customers living in the high building without elevators, it is very dangerous for courier carry large-scale things such as refrigerator, TV sets to upstairs and downstairs, which has risk of destroying things, delaying delivery speed and threatening personal security etc. Therefore, designing auxiliary tools with stair climbing functions has important meanings to solve problems of difficult to carry things upstairs and downstairs in high buildings. Semi-automatic loading mope with stair climbing with new structure, safety and stability, low cost, strong practicability, convenient application, so it has universal development prospect.
\end{abstract}

\section{Project Background and Realistic Meaning}

With the quick development of express industry, consumers need much higher requirements on express service, requiring couriers to safety and quickly send things to their houses. As for customers living in high buildings without elevators, because there is no proper special distribution device and express items are too many or too heavy, such as large-scale things of refrigerator and TV sets etc. As for buyers, in order to guarantee delivery speed, many couriers violently load and unload express items, which cause unpleasant experience. Designing intelligent carrier vehicle with climbing function at the same time satisfying many complicated road conditions has important meanings.

Research on stair climbing trolley already has long history, at present people have invented stair climbing trolley with double wheel, lever and track, but it immature, which has shortcoming such as serious situations of bumping and hitting, bad stability, in the following figure, we hope to design one kind of new semi-automatic loading mope with stair climbing, which can not only smoothly go up and go down stairs, but also it has better stability, it is applicable to every kinds of elevator.

It aims to suite work demand of couriers and guarantee safety of couriers and goods, which is convenient to realize civilized load and unload, civilized sorting and distributing, posting every kinds of express items, which can make couriers not only reduce labor capacity of carrying things by climbing stairs, guarantee safety of person and things, but also can increase work efficiency and service quality.

\section{Design Plan}

\subsection{Structure Design}

It installs motor, worm and gear reducer and 2 pieces of seats with 2 as one group. Motor is connected through coupling with worm and gear reducer, worm and gear reducer is installed in 2 rockers. 2pieces of seats with 2 as one group are respectively installed both sides of frame sideboard, it installs seat bearing between seats, one side of 2 rockers is hinged with its respective seat bearing, the other side of 2 rockers is respectively connected with one side slither of its sleeve. The other side of sleeve is connected with the complete one with coupling; it respectively installs 2 return wheels on the connection bearing located in the outer side of 2 sleeves. The other side of brace is connected with output shaft key of reducer; the other side of 2 braces is hinged with top and bottom side of sleeve. Return wheel is installed in the both outer sides of sleeve, 2 big wheels are installed in the both outer sides of frame bottom board. It can also install screw or cargo on the bottom side 
of frame.

\subsection{Function design}

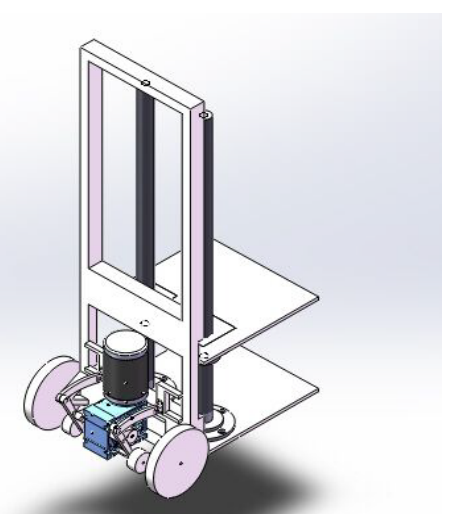

Output shaft of worn reducer drives rotation of brace, and brace drives sleeve rocker to make return wheel track motion of crescent. The return wheel is extended externally and placed onto one stair to raise trolley. When return wheel goes forward one stair, return wheel internally contracted, which places trolley onto the next stair, so that it can realize going up and down stairs.

\subsection{Analysis on labor saving of power device}

The whole stair traveling bogie is installed 2 mechanism design of labor saving which can save labor in the process of carrying heavy things, reduce burden of carrier.

Firstly is the most basic function, one brace rocker mechanism driven by electricity can make brace mechanism complete track motion of crescent through driving by motor, which can make trolley realize the process of climbing stairs to carry goods. In the process of climbing stairs, the carriers only need to control inclination angle of trolley and guarantee it is in the proper range, brace mechanism can complete the lifting process of trolley.

Secondly, the mechanism of saving labor is the elevating platform installed on the trolley structure; this elevating platform is usually used to place goods. If it needs to life goods, for example, it needs to place freight van, then it can shake hand wheel, it can be adjusted within the proper height, it can conveniently load goods onto the corresponding position.

2.4 Innovation point

(1)It uses motor as the power source of power equipment, provides power to realize power function.

(2)It applies brace rocker mechanism into equipment of climbing stairs, in the process of upstairs and downstairs, the center of gravity of trolley has little fluctuation with stable motion.

(3)Designing linkage screw equipotent to life things, which is stable and saves labor.

(4)It uses controller STM32, motor driver, semi-automatic control, which realizes mechanical-electrical integration.

\section{Detailed design and verification}

\subsection{Design on dynamic system}

\subsubsection{Choosing equipment and corresponding parameters}

According to the connecting rod structure, we need to choose proper dynamic equipment and reasonable installation structure to support operation of labor saving mechanism. Because the main part of labor saving mechanism is brace $(7.625 \mathrm{~cm})$, with complete cycle rotation, so it should choose power equipment composed of motor as well as worm and gear reducer.

Considering the large mover load as well as stair rate and coordination of people(the speed of people climbing stairs is approximately: $1 \mathrm{~s}$ per step, it is 1-4 s per step when carrying cargo). According to force analysis of link mechanism in the past, when load is $100 \mathrm{~kg}$, the brace connected with worn will receive force, then it will require the output parameter of reducer is as follows: torsion is $650 \mathrm{KG}^{*} \mathrm{CM}$, rotation rate is $15-60 \mathrm{r} / \mathrm{min}$.

Because trolley is portable, it relies on battery to be driven, at present, the usual cargo charging battery is $12 \mathrm{~V}$, in order to guarantee motor and torsion, we choose $24 \mathrm{~V}$. 
From the torsion confirmed before and primary confirmation of rotation rate range, we choose the desired reducer. By comparing with load and rotation rate, we are more prefer to choose load parameter. The more of load, it means there are too many goods to be carried one time, it is especially suitable for some large-scale home appliance or furniture delivery. So we finally confirm parameter of reducer is No 2, reduction ratios is 1: 80, unloaded speed is $21 \mathrm{r} / \mathrm{min}$, load rotation speed is $16 \mathrm{r} / \mathrm{min}$, torsion is $700 \mathrm{KGCM}$. Then the corresponding 24DC motor will accordingly complete matching.

\subsubsection{Design of installation structure}

There are 2 kinds of methods to arrange reducer output shaft direction and motor drive shaft: horizontal and vertical, in order to guarantee smaller volume of trolley(portable), and goods loading takes most part of trolley(the maximum space utilization), then installation of power equipment should possibly avoid increasing the overall volume of trolley.

The vertical arrangement of output shaft direction of reduction gear box and motor shaft is relatively shorter compared with common motor reduction motor, it is universally used in some occasions having requirements on installation dimensions, such as this mover, so we choose vertical arrangement, which is indicated by the following figure:

3.2 Design on drive system and hinge four-bar mechanism

\subsubsection{Design of brace rocker mechanism}

Because the seat has been already fixed onto main board of trolley, position of the other side of rocker is subsequently confirmed. According to height of seat away from ground, it installs reducer motor onto the proper position, so output shaft position of reducer is accordingly confirmed. Under this condition, 2 fixed points of linkage 4-bar mechanism are confirmed, at the same time, the distance from seat central point to output shaft center is $152 \mathrm{~mm}$, and then the rack length of linkage screw rod is $152 \mathrm{~mm}$.

According to the exist relevant theory knowledge, the condition for linkage 4-bar mechanism to have brace is the sum of longest rod and the shortest rod is equal or less than the sum of the remaining 2 rods, in order to prevent rocker from being collided with ground in the rotation process, it chooses rocker length is $148 \mathrm{~mm}$. Suppose length of connection rod and brace is $l_{1}$ and $l_{2}$, and $152>148>l_{1}>l_{2}$, then the condition of linkage 4-bar mechanism to be brace rocker mechanism is $152+l_{2} \leq 148+l_{1}$, then $l_{1}-l_{2} \geq 4$. Through trial value for many times, it finally confirm length of connection rod and brace is respectively $45 \mathrm{~mm}$ and $35 \mathrm{~mm}$. The actual figure and abstract figure of brace rocker are respectively indicated by the following figure.

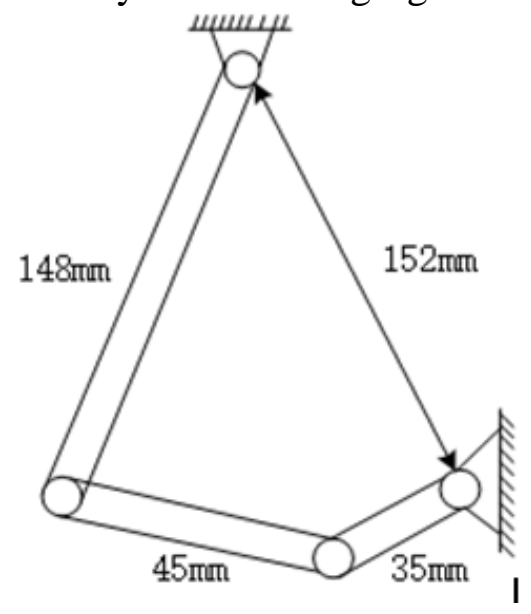

3.2.2 Design on extension length of stair climbing wheel

The trolley used for stair climbing is the key part to realize stable stair climbing, while length of trolley wheel extending connection rod needs further design. The length of trolley extending connection rod determines whether trolley can realize stair climbing function for trolley and whether trolley wheel collides with ground or not. If it is too short, then trolley wheel can not 
collide with step of the nest stage, if it is too long, then trolley will collide with ground.

By referring to relevant data, the stair step regulated by China should not larger than $210 \mathrm{~mm}$, and smaller than $140 \mathrm{~mm}$. During design, we take height of stair is $150 \mathrm{~mm}$ and further confirm length of trolley extending connection rod. By taking value for many times, it finally confirms the length of trolley extending connection rod is $80 \mathrm{~mm}$, at this time, when trolley touches with stair, the distance of wheel center away from stair edge is $40 \mathrm{~mm}$, when trolley wheel reaches the lowest point, the distance of wheel center away from stair plain is $45 \mathrm{~mm}$, all meets requirement. Both limit position is indicated by the following figure.

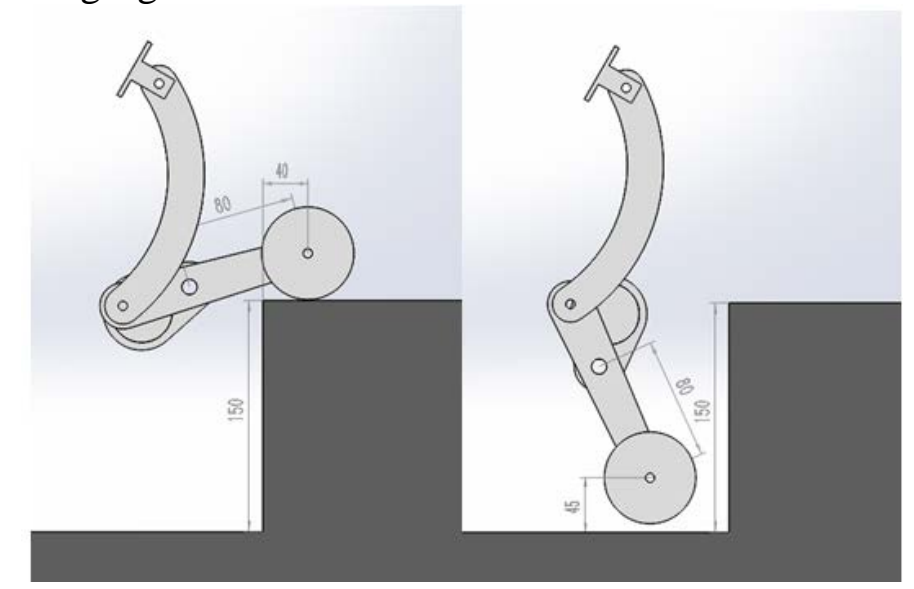

\subsection{Selection of carrier system-screw lifting mechanism}

Screw lifting machine is one kind of basic lifting part; its load capacity is from 0.5 to 300T. It has merits such as compact structure, small volume, light weight, universal power source, noiseless, convenient installation, flexible application, multiple functions, flexible affiliating way, long service life etc. It integrates many kinds of functions in lifting, descending, forwarding, rolling-over etc. It can directly use electric motor or other power to drive, it can be also driven by manual, the maximum input rotation rate is $1500 \mathrm{r} / \mathrm{min}$, and the maximum lifting speed is $2.7 / \mathrm{min}$.

As for our design plan, we finally choose specification of 2 sets of sw2-1t linkage, one set needs operate by manual, the other set needs rotating by linkage, it dose not rely on motor to drive, 2 screw rod is $1 \mathrm{~m}$, space distance between screw rod is $25 \mathrm{~cm}$. This design can save much labor in lifting heavy things; the lifting height can reach $1 \mathrm{~m}$. Rate ratio chooses percentage of 6 : 1 , which can guarantee the quickest lifting speed. The top side of screw is flange, which is convenient for fixation.

3.4 Design on control system

Control system is composed of controller STM32, motor driver, press key etc. Controller chooses ARM Cortex-0 core especially designed by embedded application of STM32F407, STM32 series requiring high performance, low cost an low consumption, while STM32F407 is one of the most excellent among STM 32 series.

Drive machine of motor chooses big power DC motor drive board module, $\mathrm{H}$ bridge, positive and negative rotation of 12/24/36V 360W, which can meet PWM characteristics, it can drive motor and control positive and negative rotation, adjust speed(here we do not use speed adjustment). Press key is only common key, it totally has 3 keys, one controls positive rotation, means pressing it, motor will positively rotate, the other one is negative rotation, and the third one is stop. When using it, firstly supplies power, pressing button of positive rotation, motor will positively rotate, pressing negative rotation, pressing stop key, motor will negatively rotate, when downstairs, pressing stop key, motor will stop working.

\section{Application methods}

When upstairs, open battery box switch, motor positively rotates and goes through coupling, drives worm and gear reducer input shaft, it can drive output shaft rotation through gear reducer affiliated by motor itself as well as worm and gear reducer, which can make brace drive sleeve and 
rocker to motion, make return wheel present clockwise motion of crescent. On upstairs, system is operating, return wheel will move according to the figure, when return wheel touches the step of the upper stage and continues to move by clockwise direction, as it is indicated by the figure, because friction makes return wheel keeps stabilizing with step of the upper stage, return wheel just moves to the lowest point of crescent curve, and it will move upwards and downwards along the curve, at this time the subsidiary pull trolley handrail towards his direction, which makes big wheel inclines towards the intentional step edge, at this time, return wheel just rotates one circle and back to the next intentional step edge, and preparing to climb toward the next step.

When downstairs, open battery box switch, motor negatively rotates and goes through coupling, drives worm and gear reducer input shaft, it can drive output shaft rotation through gear reducer affiliated by motor itself as well as worm and gear reducer, which can make brace drive sleeve and rocker to motion, make return wheel present anti-clockwise motion of crescent. Because of effect of hall sensor and permanent magnet on brace side installed on the side of worn and gear reducer, which makes return wheel stop in the pre-set reset position, as it is indicated by the figure, the handrail of trolley horizontally forwards, making big wheel hand in the air and return wheel will completely undertake the whole weight of trolley, open the downstairs battery box switch, return wheel moves upwards and outside by crescent track driven by motor, at this time return wheel still keeps stable with step due to friction, so trolley is slowly placed onto the next step, and then return wheel goes towards the highest point along track and make automatic indentation. Because of effect of hall sensor and permanent magnet on brace side installed on the side of worn and gear reducer, so that it can make return wheel stop in the reset position, preparing for the downstairs motion of the next time. And then it will repeat the same motion and go downstairs.

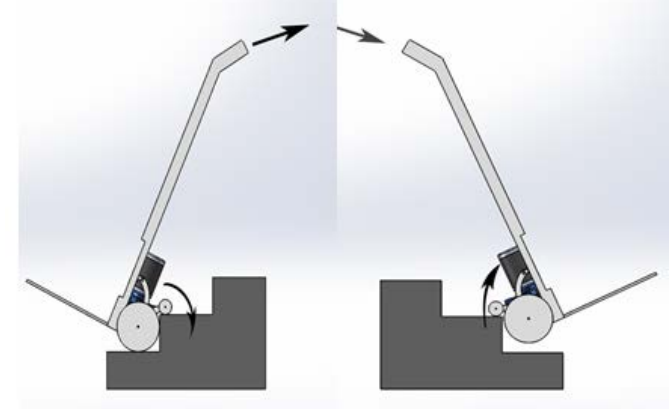

Figure 1 Motion diagram of upstairs (left) and motion diagram downstairs (right)

\section{Performance analyses}

At present, the trolley by stair climbing with double wheel, lever, rack is immature, it has serious situation of bumping and hitting, its stability is very bad.

The most obvious characteristics of stair climbing mechanism with double wheel lies in that it can be evenly distributed in Y shape or cross rod which is composed of several small wheels. Every small wheel can rotate around its axis; it can also revolve with binder around central axis. When running on the plain ground, every small wheel rotate by itself, while it is climbing stairs, every wheel is revolving together, so that it can realize function of climbing stairs. But it has serious situation of bumping and hitting, its stability is very bad, which can not accommodate to steps of different sizes, and turning is very difficult. The main characteristics of lever shape lies in that it has 2 sets of support mechanisms, both of them alternately support, so that it can realize function of upstairs and downstairs. The stairs climbing process of this mechanism is similar to the process of people upstairs and downstairs, there is also people regard it has stair climbing trolley by running. The lever trolley has obvious time delay and serious situation of bumping and hitting, its stability is not so good, it is easily to have overturning situation on improper operation. The main shortcomings of rack trolley lies in that it has heavy pressure when rack touches with stairs, which has abrasion for stairs and rack, at the same time, rack needs length of at least 3 steps, which seriously affects turning. 
When the new semi-automatic loading mope by stair climbing designed by us downstairs and upstairs, the center of gravity of trolley is always along with the connection line of stair step to motion in straight line, its center gravity has little fluctuation, and motion is very stable.

It dose not only smoothly upstairs and downstairs, its safety and stability is very good, which is applicable to step of different dimensions, it dose not have problem of wheel and step having difficulty in positioning, which has simple operation, high safety, strong practicability, it installs goods cargo on the vehicle, which can help to smoothly carry goods when upstairs and downstairs.

Because of limited technology, this product also has some shortcomings, for example, it will produce slight noise when motor is running, stable operation of linkage mechanism, installation of corresponding equipment and beautiful design of fitting pattern.

\section{Market Prospect}

At present, there are 2 kinds of carrier vehicle by stair climbing: one is to use motor as external power, which mostly introduces into foreign technology, the price is about 20000Yuan, the other one is the common tiger truck without external power, its price is about 300Yuan. The primary manufacturing cost of new semi-automatic loading mope by stair climbing is about 1000Yuan, it is believed that batch production will greatly reduce cost, the cost is predicted at 350Yuan or so. It has new structure, safe, stable with low cost, strong practicability, it is believed that it will obtain market acknowledgement and have universal market prospect.

\section{References}

[1]Wang Jiaoni. Analysis on Aging Problem in China and Research Overview of Countermeasure Strategy [J].Time Economy and Trade, 2013-6.

[2]Xiong Guangming, Zhao Tao, Gong Jianwei etc. Service Robot Development Overview and Problems Overview [J].Machine Tool, 2007,(03):213-2167.

[3]L v Guogang. Design and Research on Multi-function Explosive Ordnance Disposal Robot [D]. Southwest University of Science and Technology.2013.

[4]Lu Fenghua. Research and Analysis on Wheel Chair by Climbing Stairs [D]. Northeastern University.2007.

[5]Su Heping. Research Progress of Wheel Chair by Climbing Stairs [J]. Chinese Journal of Rehabilitation Medicine.2005,5: 366-367.

[6]Wang Zhanli, Meng Xiangyu, Chen Yanwei. Design on One Kind of Star Wheel with Electric Power by Climbing Stairs [J]. Manufacture, 2012,(10):56-58.

[7]Lu Fengqin. Research on Multi-function Stair Climbing Equipment and Design on Control System [D]. Nanjing University of Science \& Technology.2008.

[9]Xu Chang. Research on Comprehensive Performance Test Platform of Special Electric Drive Mechanism [D].Chongqing University. 2011.

[10]ZhangYan. One Kind of FEA on Electric Forklift Side Reducer [D]. Hefei University of Technology. 2013.

[13]Wen Bangchun etc. Machinerys Handbook. Volume II[M].Beijing: Machine Press, 2011.04. 